\title{
Application of black phosphorus nanodots to live cell imaging
}

\author{
Yong Cheol Shin', Su-Jin Song ${ }^{2}$, Yu Bin Lee ${ }^{2}$, Moon Sung Kang ${ }^{2}$, Hyun Uk Lee', Jin-Woo Oh \\ and Dong-Wook $\operatorname{Han}^{2^{*}}$ (D)
}

\begin{abstract}
Background: Black phosphorus (BP) has emerged as a novel class of nanomaterials owing to its unique optical and electronic properties. BP, a two-dimensional (2D) nanomaterial, is a structure where phosphorenes are stacked together in layers by van der Waals interactions. However, although BP nanodots have many advantages, their biosafety and biological effect have not yet been elucidated as compared to the other nanomaterials. Therefore, it is particularly important to assess the cytotoxicity of BP nanodots for exploring their potentials as novel biomaterials.

Methods: BP nanodots were prepared by exfoliation with a modified ultrasonication-assisted solution method. The physicochemical properties of BP nanodots were characterized by transmission electron microscopy, dynamic light scattering, Raman spectroscopy, and X-ray diffractometry. In addition, the cytotoxicity of BP nanodots against C2C12 myoblasts was evaluated. Moreover, their cell imaging potential was investigated.
\end{abstract}

Results: Herein, we concentrated on evaluating the cytotoxicity of BP nanodots and investigating their cell imaging potential. It was revealed that the BP nanodots were cytocompatible at a low concentration, although the cell viability was decreased with increasing BP nanodot concentration. Furthermore, our results demonstrated that the cells took up the BP nanodots, and the BP nanodots exhibited green fluorescence.

Conclusions: In conclusion, our findings suggest that the BP nanodots have suitable biocompatibility, and are promising candidates as fluorescence probes for biomedical imaging applications.

Keywords: Black phosphorus, Cell imaging, C2C12 myoblast, Fluorescence probe, Biomedical imaging

\section{Background}

Recently, various types of nanomaterials, such as carbon nanotube, graphene, quantum dot, and gold nanoparticle, have been proposed for a number of biomedical applications due to their distinct properties [1-5]. Among many nanomaterials, black phosphorus (BP) has emerged as a novel class of nanomaterials owing to its unique optical and electronic properties [6, 7]. BP can be readily exfoliated into nanodots because phosphorenes are stacked together in layers within bulk BP by weak van der Waals interactions [8-10]. The bandgap of exfoliated BP can be tailored according to the number of its layers $(\sim 0.3 \mathrm{eV}$ for bulk $\mathrm{BP}$ and $\sim 2 \mathrm{eV}$ for single-layer $\mathrm{BP})[7,11,12]$. In addition, $\mathrm{BP}$ possesses superior electronic properties,

\footnotetext{
*Correspondence: nanohan@pusan.ac.kr

${ }^{2}$ Department of Cogno-Mechatronics Engineering, College of Nanoscience \& Nanotechnology, Pusan National University, Busan 46241, Republic of Korea Full list of author information is available at the end of the article
}

particularly its high carrier mobility (in the order of $\left.10^{5} \mathrm{~cm}^{2} / \mathrm{V} / \mathrm{s}\right)$ and relatively high lattice thermal conductivity $(12.1 \mathrm{~W} / \mathrm{mK})$ [13-16]. The uinique puckered structure of BP can also contribute the unusual mehcanical performance, such as a negative Poisson's ratio, and unique optical properties, which show applied strain-dependent and anisotropic optical absorption spectrum [17-21]. Such unique optical and electronic properties of nano-sized BP, including an accurate optical-response property, anisotropic charge transport and semiconducting property with a layer-dependent bandgap, enable it to be employed for biomedical imaging applications $[6,10,22]$. In addition, the BP can be tailored by a variety of surface coating ligands, and it allows BP to be utilized as novel biomaterials. It has been revealed that the PEGylated BP nanosheets are internalized into cells by macropinocytosis or caveolaedependent endocytosis pathways, and can be used as a

(C) The Author(s). 2018 Open Access This article is distributed under the terms of the Creative Commons Attribution 4.0 International License (http://creativecommons.org/licenses/by/4.0/), which permits unrestricted use, distribution, and 
2D delivery platform for cancer theranostics [10]. In addition, PEGylated BP has been found to be photostable and suitable for photothermal therapy agent as well as photoacoustic imaging because it can convert near-infrared light to heat [19]. Additionally, there have been intensive efforts to employ BP in many widespread applications, such as lithium-ion rechargeable batteries, transistors, optoelectronic materials, and energy harvesting [22-25]. However, not much is known about the cytotoxicity and biological effects of BP as compared to the other nanomaterials, although BP nanodots have outstanding optical, electrical and mechanical properties. Therefore, prior to exploring their potential as novel nanomaterials, it is particularly important to assess the biosafety and biological effects of BP nanodots.

On the other hand, cell imaging is one of the highest priority for biomedical applications to fundamentally understand the biological basis of nanomaterials as well as to observe cellular behaviors. Hence, much research has been devoted to developing biofunctional imaging agents using various nanomaterials, such as quantum dots, gold nanoparticles and magnetic particles, that can be simultaneously used as diagnostic imaging and therapeutic agents [26-30]. However, the development of ideal nanomaterial-based imaging and therapeutic agents is still a challenge. In recent years, BP nanodots have attracted increasing attention in the field of biomedical imaging because of their unique optical and fluorescent characteristics $[6,19,31,32]$. Meanwhile, the biological effects of BP nanodots, including cytotoxicity issues on mammalian cells, still remain to be addressed.

Herein, we focused on the cytotoxicity of BP nanodots against mammalian cells and further investigated their cell imaging potential. BP nanodots were prepared by exfoliation with a modified ultrasonication-assisted solution method [6]. The physicochemical properties of BP nanodots were characterized by transmission electron microscopy (TEM), dynamic light scattering, Raman spectroscopy, and X-ray diffraction (XRD). In addition, the cytotoxicity of $\mathrm{BP}$ nanodots against $\mathrm{C} 2 \mathrm{C} 12$ skeletal myoblasts was determined by cell counting kit- 8 (CCK-8) assay. Furthermore, the fluorescence analysis of $\mathrm{C} 2 \mathrm{C} 12$ myoblasts treated with BP nanodots was conducted in order to explore their potential as biocompatible fluorescence probes for applications to cell and biomedical imaging.

\section{Methods}

\section{Preparation of BP nanodots}

BP nanodots were obtained by exfoliation with a modified ultrasonication-assisted solution method according to the procedure previously described $[6,33]$. Briefly, BP $(0.4 \mathrm{~g}, 12.8 \mathrm{mmol})$ was dispersed in deionized water by ultrasound sonication for $30 \mathrm{~min}$ to form several-layered $\mathrm{BP}$ nanodots. The $10 \mathrm{~mL}$ supernatant of BP suspension was transferred in fresh deionized water, and ultrasound sonicated for $10 \mathrm{~min}$. These steps were repeated three times, and finally, BP nanodots were obtained.

\section{Characterizations of BP nanodots}

The morphology of the BP nanodots was examined by TEM (H-7600, Hitachi, Tokyo, Japan) at an accelerating voltage of $80 \mathrm{kV}$. The Raman spectrum of BP nanodots was obtained by a Raman spectrometer (Micro Raman PL Mapping System, Dongwoo Optron Co., Kwangju, Korea) with excitation at $514.5 \mathrm{~nm}$ using an Ar-ion laser with a radiant power of $5 \mathrm{~mW}$. The average hydrodynamic size and zeta potential of BP nanodots were analyzed using a Zetasizer (Malvern Instruments, Nano ZS, Worcestershire, UK). The XRD pattern of BP nanodots was obtained using the X-ray diffractometer (Empyrean series 2, PANalytical, Almelo, Netherlands) with $\mathrm{Cu}-\mathrm{K} \alpha$ radiation $(\lambda=0.154 \mathrm{~nm})$ at $40 \mathrm{kV}$ and $30 \mathrm{~mA}$. The measurements were conducted in the $2 \theta$ range of $10-80^{\circ}$ with a scan rate of $2^{\circ} / \mathrm{min}$ at room temperature.

\section{Cytotoxicity evaluation of BP nanodots in $\mathrm{C} 2 \mathrm{C} 12$ skeletal myoblasts}

The $\mathrm{C} 2 \mathrm{C} 12$ mouse skeletal myoblasts were purchased from the American Type Culture Collection (Rockville, MD, USA) and routinely maintained in Dulbecco's modified Eagle's Medium (DMEM, Welgene, Daegu, Korea) supplemented with $10 \%$ fetal bovine serum (Welgene) and a $1 \%$ antibiotic-antimycotic solution (containing 10,000 units penicillin, $25 \mu \mathrm{g}$ amphotericin B and $10 \mathrm{mg}$ streptomycin per $\mathrm{mL}$, Sigma-Aldrich Co., Saint Louis, MO, USA) at $37^{\circ} \mathrm{C}$ in a humidified atmosphere containing $5 \% \mathrm{CO}_{2}$.

To assess the cytotoxicity of BP nanodots in the $\mathrm{C} 2 \mathrm{C} 12$ skeletal myoblasts, a CCK-8 assay (Dojindo, Kumamoto, Japan) was conducted according to the manufacturer's instructions. The number of viable cells was found to be directly proportional to the metabolic reaction products obtained in the CCK- 8 assay $[34,35]$. Briefly, the C2C12 myoblasts were seeded at a density of $5 \times 10^{4}$ cells $/ \mathrm{mL}$ on 24-well plates and incubated for $24 \mathrm{~h}$. After then, BP nanodots were added with increasing concentrations $(0$ to $250 \mu \mathrm{g} / \mathrm{mL}$ ) to the culture media, and the cells were further cultured for 24 and $48 \mathrm{~h}$. Subsequently, the cells were incubated with a CCK- 8 solution for an additional $2 \mathrm{~h}$ at $37{ }^{\circ} \mathrm{C}$ in the dark. The absorbance values were measured at $450 \mathrm{~nm}$ using a SpectraMax ${ }^{\circ} 340$ plate reader (Molecular Devices, Sunnyvale, CA, USA). The relative cell viability was determined as the percentage of the absorbance value in the cells to the absorbance value of a control group.

\section{Fluorescence imaging of $\mathrm{C} 2 \mathrm{C} 12$ skeletal myoblasts}

For fluorescence imaging of $\mathrm{C} 2 \mathrm{C} 12$ skeletal myoblasts treated with BP nanodots, the cells were seeded at a 
density of $5 \times 10^{4}$ cells $/ \mathrm{mL}$ on 24-well plates and incubated for $24 \mathrm{~h}$. The culture media were then replaced with fresh media containing BP nanodots at a predetermined concentration $(0.5 \mu \mathrm{g} / \mathrm{mL})$. To observe the internalization and fluorescence of BP nanodots in $\mathrm{C} 2 \mathrm{C} 12$ skeletal myoblasts, the cells were incubated for $10 \mathrm{~min}$, $30 \mathrm{~min}, 1 \mathrm{~h}, 2 \mathrm{~h}, 6 \mathrm{~h}$, and $24 \mathrm{~h}$. Subsequently, the cells treated with BP nanodots were thoroughly washed with Dulbecco's phosphate-buffered saline (SigmaeAldrich Co.) and fixed with 3.7\% formaldehyde solution (Sigma-Aldrich Co.) for $10 \mathrm{~min}$. After fixation, the nucleus was stained using propidium iodide (PI, $1 \mu \mathrm{M}$, Sigma-Aldrich Co.) solution for $15 \mathrm{~min}$, and the cells were imaged with an inverted fluorescence microscope (IX81, Olympus Optical Co., Osaka, Japan).

\section{Statistical analysis}

All variables were tested in three independent cultures for each experiment, which was repeated twice $(n=6)$. The quantitative data are expressed as the mean \pm standard deviation (SD). The data were tested for the homogeneity of the variances using the test of Levene, prior to statistical analysis. Statistical comparisons were carried out using a one-way analysis of variance (ANOVA; SAS Institute Inc., Cary, NC, USA), followed by a Bonferroni test for multiple comparisons. A value of $p<0.05$ was considered statistically significant.

\section{Results and discussion}

\section{Characterizations of BP nanodots}

The morphology of BP nanodots was observed by TEM and presented in Fig. 1a. TEM image showed the uniform spherical morphology of BP nanodots with the diameter of about several nanometers. In addition, it was shown that fine BP nanodots were clustered together into random agglomerates varying from a few nanodots to a few dozen nanodots because the freshly exfoliated BP nanodots were suspended in aqueous solution. Considering the cell culture condition, although TEM is a highly accurate technique for the characterization of nano-sized particles, their hydrodynamic size and surface charge should be considered because they would be suspended in culture media [36]. The average hydrodynamic size and zeta potential of BP nanodots were determined by dynamic light scattering and found to be $164 \pm 24 \mathrm{~nm}$ and $-12.48 \pm 0.66 \mathrm{mV}$, respectively. Therefore, it was indicated that the BP nanodots are successfully prepared from bulk BP and stably dispersed in aqueous solution, even though the hydrodynamic size of $\mathrm{BP}$ nanodots was slightly bigger than their individual size observed from TEM image.

To further confirm the successful preparation of BP nanodots, Raman spectroscopy was conducted because the BP typically exhibits specific bands, such as $A_{g}^{1}, A_{g}^{2}$ and $B_{2 g}$ modes of phosphorene [24, 37, 38]. Figure $1 b$ shows the Raman spectrum of BP nanodots. The noticeable bands were observed at 362, 440 and $469 \mathrm{~cm}^{-1}$, which were attributed to the $A_{g}^{1}, A_{g}^{2}$ and $B_{2 g}$ modes of phosphorene as reported in several previous studies $[24,37,38]$. In addition, the sharp Raman features in the spectrum implied that the BP nanodots were unique orthorhombic crystalline phosphorus structure. The orthorhombic crystalline structure of BP nanodots was also confirmed by XRD pattern (Fig. 1c). The XRD pattern of BP nanodots was found to be consistent with that of standard pattern of orthorhombic BP (JCPDS No. 76-1957). The characteristic diffraction peaks were observed at $16.9^{\circ}, 34.2^{\circ}, 52.3^{\circ}$, and $72.0^{\circ}$, corresponding to the $\mathrm{d}_{020}=5.24 \AA, \mathrm{d}_{040}=2.62 \AA, \mathrm{d}_{060}=1.75 \AA$, and $\mathrm{d}_{080}=1.31 \AA$, respectively. These results demonstrated that the BP nanodots employed in the present study were successfully prepared [24]. On the other hand, the nanometer-scale diameter of BP nanodots can greatly facilitate the interactions between BP nanodots and cells. However, the BP nanodots having nanometer-scale diameter might exhibit undesirable toxic effects on cells

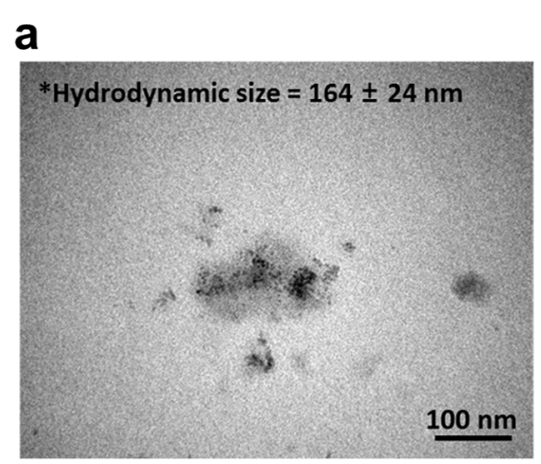

b

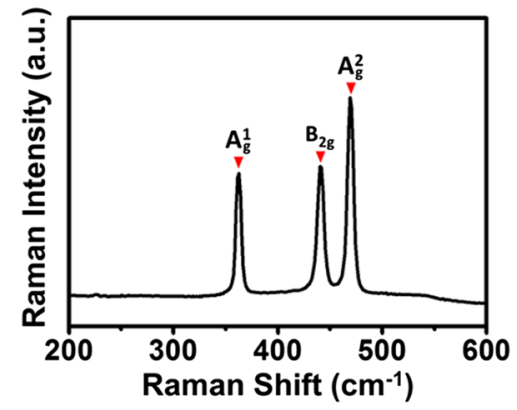

C

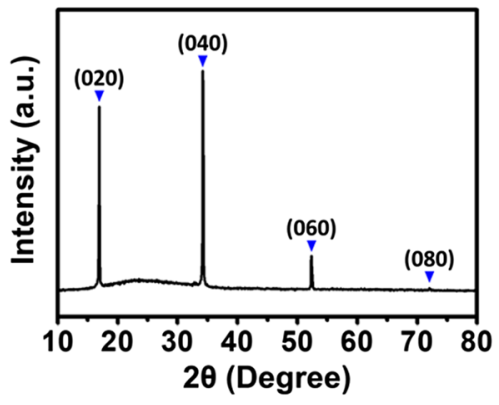

Fig. 1 Characterizations of BP nanodots. a TEM image, b Raman spectrum, c XRD pattern of BP nanodots 
and tissues that have not been found in bulk ones. Therefore, we evaluated the cytotoxic effects on $\mathrm{C} 2 \mathrm{C} 12$ murine skeletal myoblasts, prior to exploring their cell imaging potentials.

\section{Cytotoxicity of BP nanodots against C2C12 skeletal myoblasts}

The cell viability of $\mathrm{C} 2 \mathrm{C} 12$ skeletal myoblasts was determined according to the concentrations of $\mathrm{BP}$ nanodots ( 0 to $250 \mu \mathrm{g} / \mathrm{mL}$ ) by using CCK- 8 assay, based on the metabolic activity of mitochondria, in order to examine their influence on mammalian cells. As presented in Fig. 2a, the myoblast viability was decreased with increasing BP nanodot concentrations. The cell viability was significantly $(p<0.05)$ decreased at concentrations higher than $10 \mu \mathrm{g} / \mathrm{mL}$ after $24 \mathrm{~h}$ of incubation with BP nanodots, and it was approximately $30 \%$ of the control at the highest concentration $(250 \mu \mathrm{g} / \mathrm{mL})$. Meanwhile, over $84 \%$ of $\mathrm{C} 2 \mathrm{C} 12$ myoblasts were viable at a concentration of $4 \mu \mathrm{g} / \mathrm{mL}$. The cytotoxicity of BP nanodots after $48 \mathrm{~h}$ also dose-dependently increased. In addition, after longer time periods of incubation with BP nanodots

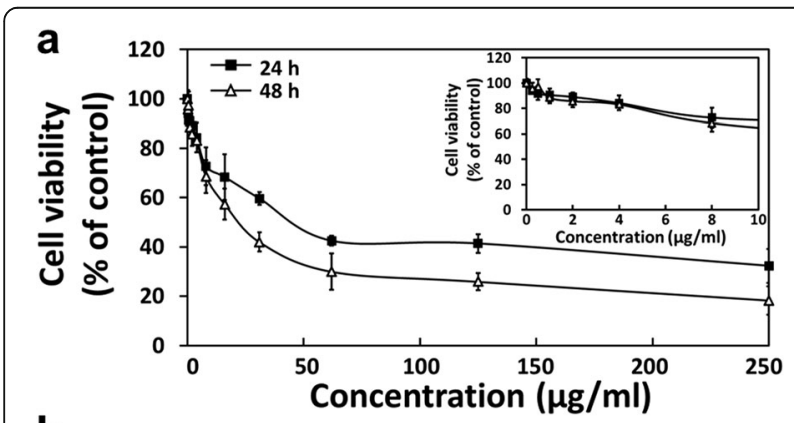

b


$200 \mu \mathrm{m}$

Fig. 2 Cytotoxicity of BP nanodots against C2C12 skeletal myoblasts. a C2C12 skeletal myoblast viability after the $24(\mathbf{\square})$ and $48 \mathrm{~h}(\triangle)$ of incubation with various concentrations of BP nanodots ( 0 to $250 \mu \mathrm{g} / \mathrm{mL}$ ). b Representative optical microscopic images of $\mathrm{C} 2 \mathrm{C} 12$ skeletal myoblasts cultured with BP nanodots $(0,0.5,4$, and $250 \mu \mathrm{g} / \mathrm{mL})$ for $24 \mathrm{~h}$. The viability of C2C12 myoblasts was determined using a CCK-8 assay, and all photographs shown in this figure are representative of six independent experiments with similar results
$(48 \mathrm{~h})$, the decrease in cell viability was more significant at concentrations higher than $10 \mu \mathrm{g} / \mathrm{mL}$. However, the cell viability was $\sim 83 \%$ at $4 \mu \mathrm{g} / \mathrm{mL}$ of BP nanodots, indicating that the BP nanodots showed little cytotoxicity at low concentrations $(\leq 4 \mu \mathrm{g} / \mathrm{mL})$. These results are in contradiction with several previous studies, which showed that there was no observable cytotoxicity $[6,39,40]$. In particular, BP nanodots were reported to show little cytotoxicity even at $1000 \mu \mathrm{g} / \mathrm{mL}$ to HeLa cell (human cervical carcinoma line), COS-7 cell (fibroblast-like monkey kidney cell line) and CHO-K1 cell (chinese hamster ovary cell) [6]. This can be attributed to the fact that nanomaterials and their derivatives exhibit cell type specific toxicity [41-44]. In the present study, BP nanodots showed significant cytotoxicity against $\mathrm{C} 2 \mathrm{C} 12$ mouse skeletal myoblasts at high concentrations $(<10 \mu \mathrm{g} / \mathrm{mL})$.

The morphological observations further support the cytotoxicity evaluation results. The morphologies of C2C12 skeletal myoblasts treated with each concentration of BP nanodots were observed by optical microscope, and the representative optical images $(0,0.5,4$, and $250 \mu \mathrm{g} / \mathrm{mL}$ of BP nanodots) were shown in Fig. $2 \mathrm{~b}$. The cells were well grown at concentrations lower than $4 \mu \mathrm{g} / \mathrm{mL}$, and there was no morphological signs of cytotoxicity. However, at a concentration of $250 \mu \mathrm{g} / \mathrm{mL} \mathrm{BP}$ nanodots, cells showed shrunken morphology, and the number of cells was significantly decreased. These results were in good accordance with the cytotoxicity profile (Fig. 2a). According to the previous literature, the cytotoxicity of nanomaterials, such as carbon nanotube, graphene and gold nanoparticles, is closely related to the intracellular reactive oxygen species (ROS) production and membrane disruption [34, 36, 45]. The cytotoxicity of BP nanodots can also have relevance to both intracellular ROS production and cell membrane disruption $[36,40]$. Meanwhile, it has been widely documented that the effects of nanomaterials are highly dependent on their concentration, size, shape, and surface charge [34-36, 46-50]. Hence, it is particularly desirable to use nano-sized BP having proper size, shape and surface charge. A series of previous studies indicate that the negatively charged particles show lower cytotoxicity than positively charged particles [47-50], and the cellular uptake of rod-shaped particles is lower than their spherical counterparts [51-53]. In addition, recent studies show that the larger BP particles $(\sim 884 \mathrm{~nm})$ have more cytotoxic effects on cells compared to the smaller ones $(\sim 209 \mathrm{~nm})[6,10,40,54]$. However, there have been also many conflicting results in the literature that may be due to variations in many other factors, such as size, particle dimension and surface functional moiety, and the effects of those factors on the cytotoxicity of BP particles may be only valid when comparing several different types of BP. The BP nanodots, used in 
the present study, exhibited cytotoxicity against $\mathrm{C} 2 \mathrm{C} 12$ myoblasts in a dose-dependent manner, but not at low concentrations $(\leq 4 \mu \mathrm{g} / \mathrm{mL})$, as consistent with previous studies that have documented that BP has good biocompatibility and can be applicable to biomedical applications, such as photoacoustic imaging and drug delivery system $[6,10,19,36,54]$. Therefore, it is suggested that BP nanodots at low concentrations have a suitable biocompatibility for their use in biomedical applications.

\section{In vitro fluorescence imaging of BP nanodots}

To explore the potential of BP nanodots as a novel cell imaging agent, in vitro fluorescence imaging was carried out. Considering the cytotoxicity evaluation results (Fig. 2), we cultured $\mathrm{C} 2 \mathrm{C} 12$ myoblasts with the $0.5 \mu \mathrm{g} / \mathrm{mL}$ of $\mathrm{BP}$ nanodots and analyzed by fluorescence microscopy. Figure 3 shows the fluorescence images of C2C12 myoblasts cultured with BP nanodots for $10 \mathrm{~min}, 30 \mathrm{~min}$, $1 \mathrm{~h}, 2 \mathrm{~h}$, and $6 \mathrm{~h}$.

The fluorescence images showed that the BP nanodots were internalized into cells as incubation time increased from 0 to $6 \mathrm{~h}$. It has been reported that the nano-sized BP can be internalized into cells via either macropinocytosis or caveolae-dependent endocytosis, and then transported through endosome and lysosome, followed by lysosomal degradation [10]. Moreover, the negatively charged surface of BP nanodots ( $-12.48 \pm$ $0.66 \mathrm{mV}$ ) can also facilitate their internalization into cells via caveolae-dependent endocytosis [49, 50]. Therefore, BP nanodots were also able to enter cells via macropinocytosis or caveolae-dependent endocytosis pathways. After
30 min of incubation with BP nanodots, the BP nanodots were accumulated in the cytoplasm, and the green fluorescence of BP nanodots was detected. Then, after more time elapsed, more BP nanodots could be internalized into cells, and accumulated in the cytoplasm, resulting in a clear green fluorescence from $\mathrm{C} 2 \mathrm{C} 12$ myoblasts. After $6 \mathrm{~h}$ of incubation, BP nanodots could be effectively internalized into $\mathrm{C} 2 \mathrm{C} 12$ myoblasts, and a strong green fluorescence was exhibited from BP nanodots concentrated in myoblasts. To clearly verify the fluorescence imaging potential of BP nanodots, the fluorescence images were taken after allowing sufficient time $(24 \mathrm{~h})$ for the BP nanodots to be internalized into cells (Fig. 4).

As shown in Fig. 4, the cells were favorably grown with $0.5 \mu \mathrm{g} / \mathrm{mL}$ BP nanodots showing typical spindle-like morphology. Notably, during the culture period, no observable cytotoxicity was detected. Moreover, the strong green fluorescence was exhibited from the BP nanodots in the cytoplasm of $\mathrm{C} 2 \mathrm{C} 12$ myoblasts. It has been acknowledged that the graphene-based nanomaterials or transition-metal dichalcogenides, such as $\mathrm{WS}_{2}$ and $\mathrm{MoS}_{2}$, are able to serve as a platform for biomedical imaging [55-60]. However, such graphene- or transitionmetal dichalcogenide-based nanomaterials are not biochemically degradable, which in turn, it has been largely restricted to their application for biomedical applications due to inadequate clearance from the organs and tissues $[6,61-64]$. On the other hand, the BP nanodots can be biochemically degraded by the internalization into cells via macropinocytosis or caveolae-dependent endocytosis pathways, followed by lysosomal degradation, and favorably cleared from organs and tissues during blood





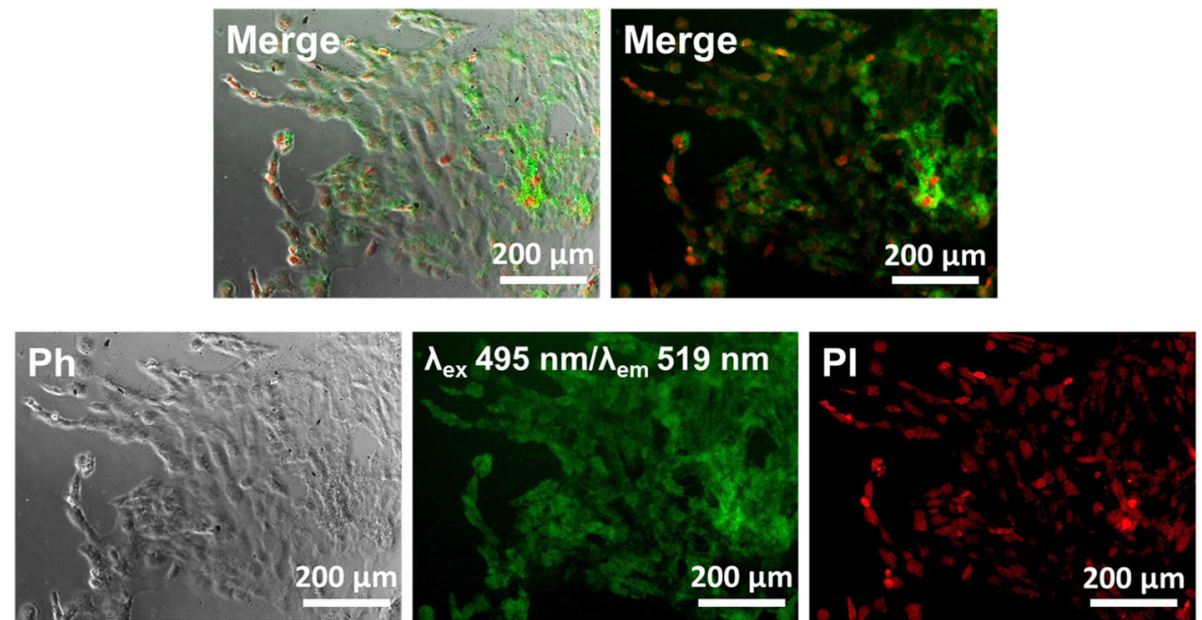

Fig. 4 In vitro fluorescence imaging of BP nanodots. Fluorescence images of $\mathrm{C} 2 \mathrm{C} 12$ skeletal myoblasts treated with $0.5 \mu \mathrm{g} / \mathrm{mL}$ of $\mathrm{BP}$ nanodots for $24 \mathrm{~h}$. Cell nuclei were counterstained with PI (red). All photographs shown in this figure are representative of six independent experiments with similar results

circulation $[6,10,65]$. BP nanodots have been recently known to not only have unique optical and electronic properties but to also possess specific fluorescence properties.

The BP nanomaterials can exhibit blue- and green-emission $\left(\lambda_{\mathrm{em}}=461\right.$ and $\left.519 \mathrm{~nm}\right)$ under ultraviolet $(\mathrm{UV})$ and visible light excitation $\left(\lambda_{\mathrm{ex}}=358\right.$ and $\left.495 \mathrm{~nm}\right)$, respectively [6]. However, the UV light has been extensively recognized to induce significantly optical damages by activating apoptosis signaling pathway as well as the production of ROS [66-69]. Hence, we observed myoblasts treated with BP nanodots under visible excitation $\left(\lambda_{\mathrm{ex}}=495 \mathrm{~nm}\right.$ and $\left.\lambda_{\mathrm{em}}=519 \mathrm{~nm}\right)$. As revealed in Fig. 4, the BP nanodots were successfully internalized into C2C12 myoblasts, concentrated in their cytoplasm, and exhibited a specific green fluorescence without undesirable cytotoxic effects. These results implied that the BP nanodots can be used as novel intrinsic fluorescence probes for biomedical applications. In addition, recent studies have revealed that the nano-sized BP have promising potential as drug delivery carrier, photothermal/photodynamic therapy agent and photodetector $[6,8,10,31,54,65]$. Moreover, BP nanodots can be functionalized with various surface groups tailored for target applications, such as drug delivery, photother$\mathrm{mal} /$ photodynamic therapy and photodetection, thus allowing the BP nanodots to be a promising candidate as novel biofunctional materials for biomedical applications. However, the more detailed biological effects of BP nanodots are still largely unknown, and further comprehensive studies should be performed before their clinical applications. Nonetheless, our preliminary studies on the potential of BP nanodots suggest that the BP nanodots can be employed as promising fluorescence probes for applications to cell and biomedical imaging.

\section{Conclusions}

This study was designed to evaluate the cytotoxicity of BP nanodots and to explore their potential for cell imaging. We successfully prepared BP nanodots by exfoliation using a modified ultrasonication-assisted solution method. The BP nanodots were found to have a nanoscale-size, indicating that the BP nanodots consisted of several layers of BP. In addition, from the cytotoxicity evaluation using $\mathrm{C} 2 \mathrm{C} 12$ skeletal myoblasts, it was revealed that the $\mathrm{BP}$ nanodots showed a dose-dependent cytotoxicity, and were cytocompatible at low concentrations $(\leq 4 \mu \mathrm{g} / \mathrm{mL})$. Moreover, our results demonstrated that the BP nanodots could be easily internalized into $\mathrm{C} 2 \mathrm{C} 12$ skeletal myoblasts, and exhibited green fluorescence under visible light excitation without undesirable cytotoxic effects. Our findings suggest that the BP nanodots have a suitable biocompatibility, and are promising candidates as fluorescence probes for biomedical imaging applications, although further comprehensive studies with BP nanodots are needed to employ the BP nanodots for in vivo and clinical applications.

\section{Abbreviations}

ANOVA: Analysis of variance; BP: Black phosphorus; CCK-8: Cell counting kit-8; DMEM: Dulbecco's modified Eagle's Medium; PI: Propidium iodide; ROS: Reactive oxygen species; SD: Standard deviation; TEM: Transmission electron microscopy; UV: Under ultraviolet; XRD: X-ray diffraction

\section{Funding}

This research was supported by Basic Science Research Program through the National Research Foundation (NRF) of Korea funded by the Ministry of Education (No. 2016R1D1A1B03931076) and a grant of the Korea Health Technology R\&D Project through the Korea Health Industry Development Institute (KHIDI) funded by the Ministry of Health \& Welfare, Republic of Korea (HI17C1662).

Availability of data and materials

All data generated or analyzed during this study are included in this published article. 


\section{Authors' contributions}

YCS and SJS designed the experiments, contributed in the cell cultures and in vitro assays, and drafted the manuscript. YBL and MSK participated in the acquisition of the fluorescence images. HUL prepared the BP nanodots, carried out the characterizations of BP nanodots, performed the statistical analysis and helped interpret the data. JWO conducted and interpreted the X-ray diffractometry. DWH conceived of the study, participated in its design and coordination, and helped to draft the manuscript. All authors read and approved the final manuscript.

\section{Ethics approval and consent to participate}

Not applicable.

\section{Consent for publication}

Not applicable.

\section{Competing interests}

The authors declare that they have no competing interests.

\section{Publisher's Note}

Springer Nature remains neutral with regard to jurisdictional claims in published maps and institutional affiliations.

\section{Author details}

${ }^{1}$ Research Center for Energy Convergence Technology, Pusan National University, Busan 46241, Republic of Korea. ${ }^{2}$ Department of Cogno-Mechatronics Engineering, College of Nanoscience \& Nanotechnology, Pusan National University, Busan 46241, Republic of Korea. ${ }^{3}$ Advanced Nano-Surface Research Group, Korea Basic Science Institute (KBSI), Daejeon 34133, Republic of Korea. ${ }^{4}$ Department of Nanofusion Technology, College of Nanoscience \& Nanotechnology, Pusan National University, Busan 46241, Republic of Korea.

\section{Received: 23 July 2018 Accepted: 25 September 2018}

\section{Published online: 04 October 2018}

\section{References}

1. Oliveira SF, Bisker G, Bakh NA, Gibbs SL, Landry MP, Strano MS. Protein functionalized carbon nanomaterials for biomedical applications. Carbon. 2015:95:767-79

2. Shin YC, Song S-J, Shin D-M, Oh J-W, Hong SW, Choi YS, et al. Nanocomposite scaffolds for myogenesis revisited: functionalization with carbon nanomaterials and spectroscopic analysis. Appl Spectrosc Rev. 2017; 53(2-4):129-56.

3. Shin YC, Song S-J, Hong SW, Jeong SJ, Chrzanowski W, Lee J-C, et al. Multifaceted biomedical applications of functional graphene nanomaterials to coated substrates, patterned arrays and hybrid scaffolds. Nanomaterials. 2017:7(11):369

4. Yi G, Son J, Yoo J, Park C, Koo H. Application of click chemistry in nanoparticle modification and its targeted delivery. Biomater Res. 2018:22(1):13.

5. Kang E-S, Kim D-S, Suhito IR, Lee W, Song I, Kim T-H. Two-dimensional material-based bionano platforms to control mesenchymal stem cell differentiation. Biomater Res. 2018;22(1):10

6. Lee HU, Park SY, Lee SC, Choi S, Seo S, Kim H, et al. Black phosphorus (BP) nanodots for potential biomedical applications. Small. 2016;12(2):214-9.

7. Batmunkh M, Bat-Erdene M, Shapter JG. Phosphorene and phosphorenebased materials-prospects for future applications. Adv Mater. 2016;28(39): 8586-617.

8. Wang H, Yang X, Shao W, Chen S, Xie J, Zhang X, et al. Ultrathin black phosphorus nanosheets for efficient singlet oxygen generation. J Am Chem Soc. 2015:137(35):11376-82.

9. Erande MB, Pawar MS, Late DJ. Humidity sensing and photodetection behavior of electrochemically exfoliated atomically thin-layered black phosphorus nanosheets. ACS Appl Mater Interfaces. 2016;8(18):11548-56.

10. Tao W, Zhu X, Yu X, Zeng X, Xiao Q, Zhang X, et al. Black phosphorus nanosheets as a robust delivery platform for cancer theranostics. Adv Mater. 2017;29(1):1603276.

11. Tran V, Soklaski R, Liang Y, Yang L. Layer-controlled band gap and anisotropic excitons in few-layer black phosphorus. Phys Rev B. 2014;89(23):235319.
12. Woomer AH, Farnsworth TW, Hu J, Wells RA, Donley CL, Warren SC. Phosphorene: synthesis, scale-up, and quantitative optical spectroscopy. ACS Nano. 2015;9(9):8869-84

13. Akahama Y, Endo S. Narita S-i. electrical properties of black phosphorus single crystals. J Phys Soc Jpn. 1983;52(6):2148-55.

14. Morita A. Semiconducting black phosphorus. Appl Phys A Mater Sci Process. 1986;39(4):227-42.

15. Zhang J, Liu HJ, Cheng L, Wei J, Liang JH, Fan DD, et al. Phosphorene nanoribbon as a promising candidate for thermoelectric applications. Sci Rep. 2014;4:6452.

16. Flores E, Ares JR, Castellanos-Gomez A, Barawi M, Ferrer IJ, Sánchez C. Thermoelectric power of bulk black-phosphorus. Appl Phys Lett. 2015; 106(2):022102

17. Çakır D, Sahin H, Peeters FM. Tuning of the electronic and optical properties of single-layer black phosphorus by strain. Phys Rev B. 2014;90(20):205421.

18. Hu T, Hashmi A, Hong J. Geometry, electronic structures and optical properties of phosphorus nanotubes. Nanotechnology. 2015;26(41):415702.

19. Sun C, Wen L, Zeng J, Wang Y, Sun Q, Deng L, et al. One-pot solventless preparation of PEGylated black phosphorus nanoparticles for photoacoustic imaging and photothermal therapy of cancer. Biomaterials. 2016;91:81-9.

20. Wei Q, Peng X. Superior mechanical flexibility of phosphorene and fewlayer black phosphorus. Appl Phys Lett. 2014;104(25):251915.

21. Jiang J-W, Park HS. Mechanical properties of single-layer black phosphorus. J Phys D Appl Phys. 2014;47(38):385304.

22. Buscema M, Groenendijk DJ, Steele GA, van der HSJ Z, Castellanos-Gomez A. Photovoltaic effect in few-layer black phosphorus PN junctions defined by local electrostatic gating. Nat Commun. 2014;5:4651.

23. Park CM, Sohn HJ. Black phosphorus and its composite for lithium rechargeable batteries. Adv Mater. 2007;19(18):2465-8.

24. Xia F, Wang H, Jia Y. Rediscovering black phosphorus as an anisotropic layered material for optoelectronics and electronics. Nat Commun. 2014;5:4458.

25. Wood JD, Wells SA, Jariwala D, Chen K-S, Cho E, Sangwan VK, et al. Effective passivation of exfoliated black phosphorus transistors against ambient degradation. Nano Lett. 2014;14(12):6964-70.

26. Saitoh Y, Terada N, Saitoh S, Ohno N, Jin T, Ohno S. Histochemical analyses and quantum dot imaging of microvascular blood flow with pulmonary edema in living mouse lungs by "in vivo cryotechnique". Histochem Cell Biol. 2012;137(2):137-51.

27. Hainfeld JF, Smilowitz HM, O'Connor MJ, Dilmanian FA, Slatkin DN. Gold nanoparticle imaging and radiotherapy of brain tumors in mice. Nanomedicine. 2013;8(10):1601-9.

28. Bauer LM, Situ SF, Griswold MA, Samia ACS. High-performance iron oxide nanoparticles for magnetic particle imaging-guided hyperthermia (hMPI). Nanoscale. 2016:8(24):12162-9.

29. Tran VT, Kim J, Tufa LT, Oh S, Kwon J, Lee J. Magnetoplasmonic nanomaterials for biosensing/imaging and in vitro/in vivo biousability. Anal Chem. 2017;90(1):225-39.

30. Jeong $Y, N a$ K. Synthesis of a gadolinium based-macrocyclic MRI contrast agent for effective cancer diagnosis. Biomater Res. 2018;22(1):17.

31. Engel M, Steiner M, Avouris P. Black phosphorus photodetector for multispectral, high-resolution imaging. Nano Lett. 2014;14(11):6414-7.

32. Lu SB, Miao LL, Guo ZN, Qi X, Zhao CJ, Zhang H, et al. Broadband nonlinear optical response in multi-layer black phosphorus: an emerging infrared and mid-infrared optical material. Opt Express. 2015;23(9):11183-94.

33. Lee HU, Lee SC, Won J, Son B-C, Choi S, Kim Y, et al. Stable semiconductor black phosphorus (BP)@titanium dioxide $\left(\mathrm{TiO}_{2}\right)$ hybrid photocatalysts. Sci Rep. 2015;5:8691.

34. Lee JH, Shin YC, Jin OS, Lee EJ, Han D-W, Kang SH, et al. Cytotoxicity evaluations of pristine graphene and carbon nanotubes in fibroblastic cells. J Korean Phys Soc. 2012;61(6):873-7.

35. Shin YC, Lee JH, Kim MJ, Hong SW, Kim B, Hyun JK, et al. Stimulating effect of graphene oxide on myogenesis of $\mathrm{C} 2 \mathrm{C} 12$ myoblasts on RGD peptidedecorated PLGA nanofiber matrices. J Biol Eng. 2015;9(1):22.

36. Song S-J, Shin YC, Lee HU, Kim B, Han D-W, Lim D. Dose- and timedependent cytotoxicity of layered black phosphorus in fibroblastic cells. Nanomaterials. 2018;8(6):408.

37. Brent JR, Savjani N, Lewis EA, Haigh SJ, Lewis DJ, O'Brien P. Production of few-layer phosphorene by liquid exfoliation of black phosphorus. Chem Commun. 2014;50(87):13338-41.

38. Liu H, Neal AT, Zhu Z, Luo Z, Xu X, Tománek D, et al. Phosphorene: an unexplored 2D semiconductor with a high hole mobility. ACS Nano. 2014; 8(4):4033-41. 
39. Sun Z, Xie H, Tang S, Yu XF, Guo Z, Shao J, et al. Ultrasmall black phosphorus quantum dots: synthesis and use as photothermal agents. Angew Chem. 2015;127(39):11688-92.

40. Zhang X, Zhang Z, Zhang S, Li D, Ma W, Ma C, et al. Size effect on the cytotoxicity of layered black phosphorus and underlying mechanisms. Small. 2017;13(32):1701210

41. Peng J, Gao W, Gupta BK, Liu Z, Romero-Aburto R, Ge L, et al. Graphene quantum dots derived from carbon fibers. Nano Lett. 2012;12(2):844-9.

42. Shang W, Zhang X, Zhang M, Fan Z, Sun Y, Han M, et al. The uptake mechanism and biocompatibility of graphene quantum dots with human neural stem cells. Nanoscale. 2014;6(11):5799-806.

43. Gokhale R, Singh P. Blue luminescent graphene quantum dots by photochemical stitching of small aromatic molecules: fluorescent nanoprobes in cellular imaging. Part Part Syst Charact. 2014;31(4):433-8.

44. Sohaebuddin SK, Thevenot PT, Baker D, Eaton JW, Tang LP. Nanomaterial cytotoxicity is composition, size, and cell type dependent. Part Fibre Toxicol. 2010;7:22.

45. Akhavan O, Ghaderi E, Akhavan A. Size-dependent genotoxicity of graphene nanoplatelets in human stem cells. Biomaterials. 2012;33(32):8017-25.

46. Kim MJ, Lee JH, Shin YC, Jin L, Hong SW, Han D-W, et al. Stimulated myogenic differentiation of $\mathrm{C} 2 \mathrm{C} 12$ murine myoblasts by using graphene oxide. J Korean Phys Soc. 2015;67(11):1910-4.

47. Asati A, Santra S, Kaittanis C, Perez JM. Surface-charge-dependent cell localization and cytotoxicity of cerium oxide nanoparticles. ACS Nano. 2010; 4(9):5321-31.

48. Bhattacharjee S, de Haan LHJ, Evers NM, Jiang X, Marcelis ATM, Zuilhof $H$, et al. Role of surface charge and oxidative stress in cytotoxicity of organic monolayer-coated silicon nanoparticles towards macrophage NR8383 cells. Part Fibre Toxicol. 2010;7(1):25.

49. Fröhlich $\mathrm{E}$. The role of surface charge in cellular uptake and cytotoxicity of medical nanoparticles. Int J Nanomedicine. 2012;7:5577.

50. Bhattacharjee S, Ershov D, Jvd G, Alink GM, IMCM R, Zuilhof H, et al. Surface charge-specific cytotoxicity and cellular uptake of tri-block copolymer nanoparticles. Nanotoxicology. 2013;7(1):71-84

51. Chithrani BD, Ghazani AA, Chan WCW. Determining the size and shape dependence of gold nanoparticle uptake into mammalian cells. Nano Lett. 2006;6(4):662-8

52. Wang S, Lu W, Tovmachenko O, Rai US, Yu H, Ray PC. Challenge in understanding size and shape dependent toxicity of gold nanomaterials in human skin keratinocytes. Chem Phys Lett. 2008:463(1-3):145-9.

53. Hamilton RF, Wu N, Porter D, Buford M, Wolfarth M, Holian A. Particle length-dependent titanium dioxide nanomaterials toxicity and bioactivity. Part Fibre Toxicol. 2009;6(1):35.

54. Chen W, Ouyang J, Liu H, Chen M, Zeng K, Sheng J, et al. Black phosphorus nanosheet-based drug delivery system for synergistic photodynamic/ photothermal/chemotherapy of cancer. Adv Mater. 2017;29(5):1603864.

55. Sun X, Liu Z, Welsher K, Robinson JT, Goodwin A, Zaric S, et al. Nano-graphene oxide for cellular imaging and drug delivery. Nano Res. 2008;1(3):203-12.

56. Yang K, Hu L, Ma X, Ye S, Cheng L, Shi X, et al. Multimodal imaging guided photothermal therapy using functionalized graphene nanosheets anchored with magnetic nanoparticles. Adv Mater. 2012;24(14):1868-72.

57. Nurunnabi MD, Khatun Z, Reeck GR, Lee DY, Lee Y-k. Near infra-red photoluminescent graphene nanoparticles greatly expand their use in noninvasive biomedical imaging. Chem Commun. 2013;49(44):5079-81.

58. Cheng L, Liu J, Gu X, Gong H, Shi X, Liu T, et al. PEGylated WS, nanosheets as a multifunctional theranostic agent for in vivo dual-modal CT/ photoacoustic imaging guided photothermal therapy. Adv Mater. 2014; 26(12):1886-93.

59. Liu T, Shi S, Liang C, Shen S, Cheng L, Wang C, et al. Iron oxide decorated $\mathrm{MoS}_{2}$ nanosheets with double PEGylation for chelator-free radiolabeling and multimodal imaging guided photothermal therapy. ACS Nano. 2015;9(1): 950-60

60. Li Z, Wong SL. Functionalization of 2D transition metal dichalcogenides for biomedical applications. Mater Sci Eng C. 2017;70:1095-106.

61. Duch MC, Budinger GRS, Liang YT, Soberanes S, Urich D, Chiarella SE, et al. Minimizing oxidation and stable nanoscale dispersion improves the biocompatibility of graphene in the lung. Nano Lett. 2011;11(12):5201-7.

62. Zhang $X$, Yin J, Peng C, Hu W, Zhu Z, Li W, et al. Distribution and biocompatibility studies of graphene oxide in mice after intravenous administration. Carbon. 2011:49(3):986-95.
63. Jakus AE, Secor EB, Rutz AL, Jordan SW, Hersam MC, Shah RN. Threedimensional printing of high-content graphene scaffolds for electronic and biomedical applications. ACS Nano. 2015;9(4):4636-48.

64. Hao J, Song G, Liu T, Yi X, Yang K, Cheng L, et al. In vivo long-term biodistribution, excretion, and toxicology of PEGylated transition-metal dichalcogenides $\mathrm{MS}_{2}$ (M = Mo, W, Ti) nanosheets. Adv Sci. 2017;4(1):1600160.

65. Shao J, Xie H, Huang H, Li Z, Sun Z, Xu Y, et al. Biodegradable black phosphorus-based nanospheres for in vivo photothermal cancer therapy. Nat Commun. 2016:7:12967.

66. Kramer GF, Ames BN. Oxidative mechanisms of toxicity of low-intensity near-UV light in Salmonella typhimurium. J Bacteriol. 1987:169(5):2259-66.

67. Imlay JA, Linn S. DNA damage and oxygen radical toxicity. Science. 1988; 240(4857):1302-9.

68. Stierner U, Rosdahl I, Augustsson A, Kãgedal B. UVB irradiation induces melanocyte increase in both exposed and shielded human skin. J Invest Dermatol. 1989;92(4):561-4

69. Zhuang L, Wang B, Sauder DN. Molecular mechanism of ultraviolet-induced keratinocyte apoptosis. J Interf Cytokine Res. 2000;20(5):445-54

\section{Ready to submit your research? Choose BMC and benefit from:}

- fast, convenient online submission

- thorough peer review by experienced researchers in your field

- rapid publication on acceptance

- support for research data, including large and complex data types

- gold Open Access which fosters wider collaboration and increased citations

- maximum visibility for your research: over $100 \mathrm{M}$ website views per year

At $\mathrm{BMC}$, research is always in progress.

Learn more biomedcentral.com/submissions 